\title{
NUTRITIONAL POTENTIAL OF SUPERCRITICAL FLUID-EXTRACTED PALM FRUIT
}

\section{SOEK SIN TEH ${ }^{1 *}$; NATALIE VIVIEN GUNTER ${ }^{1,2}$ and HARRISON LIK NANG LAU ${ }^{1}$}

\begin{abstract}
Supercritical-fluid extraction (SFE) has been suggested to be highly suitable method for food processing due to its greener approach and use of readily available and safe solvents. The palm fruit fibres (PFF) have limited food applications and are often regarded as waste despite being a potential source of dietary fibre. Therefore, the aims of the study were to study the nutritional attributes and chemical composition of SFEextracted palm oil (SFE-O) and fibre (SFE-F). Results showed that SFE-O has comparable phytonutrients and oil quality with hexane-(HEX-O) and commercial mechanical pressing (MP-O)-extracted crude palm oils. Although SFE-O contains lower concentrations of phytonutrients (total of carotenoids, vitamin $E$, squalene and sterols) than the two oils, it exhibited higher antioxidant effects than MP-O as showed in 2,2-diphenyl-1-picrylhdrazyl (DPPH) radical scavenging, hydrogen peroxide $\left(\mathrm{H}_{2} \mathrm{O}_{2}\right)$ scavenging and ferric ion chelating assays, whereas SFE-O also exhibited higher ferric ion chelating activity than HEX-O, postulating its protective health benefits. Meanwhile, both SFE-fibre and HEX-fibre contain comparable dietary fibre with existing food products, suggesting the potential of PFF as a source of dietary fibre and other food applications. The beneficial effects of SFE-O and PFF also suggested that recovery of both would potentially generate additional revenue for palm oil mills.
\end{abstract}

\section{Keywords: antioxidants, dietary fibre, mechanical pressing extraction, solvent extraction, waste-to-wealth.}

Received: 11 March 2021; Accepted: 25 August 2021; Published online: 8 November 2021.

\section{INTRODUCTION}

Palm oil is commonly used in the food industry and known for its balanced ratio of saturated and unsaturated fatty acids, zero content of trans fatty acids and a variety of beneficial active compounds including phenolic compounds, phytosterols and squalene. The presence of tocopherols, tocotrienols and carotenoids in palm oil with notable antioxidant activities which enhances its nutritional value and dietary benefits when incorporated in our daily diet (Kushairi et al., 2019). However, active compounds such as polyphenols are commonly sensitive to processing conditions during the oil extraction and

\footnotetext{
Malaysian Palm Oil Board (MPOB),

6 Persiaran Institusi, Bandar Baru Bangi,

43000 Kajang, Selangor, Malaysia.

2 School of Biosciences,

Taylor's University, Lakeside Campus,

47500 Subang Jaya, Selangor, Malaysia.

* Corresponding author e-mail: ssteh@mpob.gov.my
}

refining, rendering it susceptible to degradation (Ruiz-Marcial et al., 2007). This becomes one of the driving factors to find alternative methods of oil extraction with milder conditions in order to preserve these antioxidants.

The conventional extraction of oil from palm fruits using mechanical screw-press generally involves sterilisation, digestion, clarification and drying. Another common extraction method is by using organic solvents, most commonly hexane, which is widely implemented within the industry of seed oil extraction and fractionations, owing to its high oil recovery capacity. Nonetheless, the extracted oil via this solvent extraction has been criticised for its use in the food industry as the resulting residual solvent could be harmful to both human health and the environment (Galle et al., 2003). While the simple process and generally lower cost are attractive, however, the arising limitations combined with the demand for high quality oil have prompted the search for environmentally-friendly 
alternative extraction methods that pose minimal risk to the human health (Ialenti et al., 1992). The supercritical fluid extraction (SFE) now, emerges as a potential alternative extraction process and has since been received as a safe method. Carbon dioxide $\left(\mathrm{CO}_{2}\right)$, the most commonly used solvent for SFE, is an inert, inexpensive solvent which has low critical temperature and pressure. These characteristics allow extraction using gentler conditions while leaving no solvent residues and thermally degraded active compounds in the extract. Thus, $\mathrm{SFE}-\mathrm{CO}_{2}$ has been suggested to be highly suitable for the extraction of thermally labile products. Furthermore, SFE- $\mathrm{CO}_{2}$ extracts have been accepted for the processing of food products as they are generally recognised as safe, attributed to its non-toxic and non-flammable character of $\mathrm{CO}_{2}$. In fact, the use of SFE- $\mathrm{CO}_{2}$ for palm oil extraction has thus, been previously studied and published in literature ( Ialenti et al., 1992; Lau et al., 2006).

In Malaysia, about 5.8 million hectares of land has been used to cultivate oil palm (Kushairi et al., 2019). Generally, oil palm produces approximately $10 \%$ of oil and the remaining $90 \%$ is oil palm biomass (OPB) in the form of oil palm frond $(36.9 \%)$, palm oil mill effluent $(27.1 \%)$, empty fruit bunches (10.4\%), palm fruit fibres (PFF) $(5.4 \%)$, oil palm trunk $(4.5 \%)$ and palm kernel shell $(3.1 \%)$ (Loh, 2017; Yeo et al., 2020). The biomass can be obtained from oil palm plantations and palm oil milling activities. In general, pre-treatment of OPB can be achieved by biological, physical, chemical, or physiochemical methods. All these methods resulted in either chemical or physical changes of the biomass. Physical pre-treatment involves grinding (Barakat et al., 2015), steaming and steam extrusion (Hendriks and Zeeman, 2009; Duque et al., 2016; Lin et al., 2012), thermal-mechanical extrusion (Lin et al., 2012) or ultrasonication (Subhedar and Gogate, 2016), whereas chemical pre-treatment involves the utilisation of acids (Noparat et al., 2015), alkali (Chen et al., 2013), organic solvents (Park et al., 2017) or ionic liquids (Elgharbawy et al., 2016), as well as oxidation reaction ( $\mathrm{Li}$ et al., 2013). Physicochemical methods include steam (Pielhop et al., 2016), supercritical $\mathrm{CO}_{2}\left(\mathrm{SC}-\mathrm{CO}_{2}\right)$ explosion (Zheng et al., 1995) and ammonia fibre explosion (AFEX) (Alizadeh et al., 2005). On the other hand, biological method involves the utilisation of microbial communities (Amin et al., 2017). Nevertheless, there are challenges associated with the pre-treatment methods, primarily due to the energy intensive processes such as high temperature and high pressure, along with expensive chemical reagents involved. Therefore, finding alternative methods that can prevail over these limitations are crucial.

Meanwhile, the use of the remaining PFF, after palm oil extraction is still limited. The fibres mixed with palm shells are most commonly recycled as boiler fuel for steam and electricity production (Kwong et al., 2017). Several studies highlighted the main utilisation of the biomass for solid biofuel and bio-composite production.

Nonetheless, the functional and economic potential of the fibres have yet to be realised with very little information on its nutritional value. In its original form, the major fibre components of palm fruit i.e. cellulose, hemicellulose and lignin are determined as insoluble fibre (Abdul Aziz et al., 2011). Numerous benefits of dietary fibre (DF) on human metabolism and physiology have been established in literature over the past years. For example, the intake of DF has been associated with the reduced risk of diabetes, cardiovascular diseases, certain gastrointestinal disorders and improve immune function (Anderson et al., 2009). Thus, this preliminary characterisation of the fibre content of PFF, including the total dietary fibre (TDF), insoluble dietary fibre (IDF) and soluble dietary fibre (SDF) should initially be done which would subsequently shed light on its potential for downstream applications in the food industry.

In the present study, SFE- $\mathrm{CO}_{2}$ and hexane extractions were carried out to extract crude palm oil (CPO) from palm fruits. The two extracted CPO are termed SFE-extracted palm oil (SFE-O) and hexane- (HEX-O), respectively. These two oils and commercial mechanically pressed $\mathrm{CPO}$ termed MP-O, were characterised and analysed for their oil compositions and quality, including free fatty acid (FFA) content, peroxide value (PV), phosphorus content, fatty acid composition (FAC), total carotenoid content, vitamin E content, squalene and sterols contents, total phenolic content (TPC) and total flavonoid content (TFC). This was followed by evaluation of antioxidant activities using various antioxidant assays, including 2,2-diphenyl-1picrylhdrazyl (DPPH) radical scavenging, hydrogen peroxide $\left(\mathrm{H}_{2} \mathrm{O}_{2}\right)$ scavenging, ferrous ion chelating (FIC) and ferric reducing antioxidant power (FRAP) assays. The chemical composition and DF content of the extractive-free PFF were evaluated on its potential nutritional applications.

\section{MATERIALS AND METHODS}

\section{Materials}

The sterilised palm fruits were collected from a local palm oil mill (Labu, Malaysia). The fruits were separated into two batches for the hexane and supercritical extraction methods.

The sterilised palm fruits were peeled and dried in an oven, followed by grinding to break up the fibres. The palm fruits were then subjected 
to Soxhlet extraction with hexane at $70^{\circ} \mathrm{C}$ for $8 \mathrm{hr}$. Hexane was evaporated using a rotary evaporator until a constant weight of oil was achieved. PFF was collected from the extraction thimble and was left to dry overnight in a fume hood at room temperature. The hexane-extracted $\mathrm{CPO}$ is denoted as HEX-O while the fibre is marked as HEX-F.

Meanwhile, the sterilised palm fruits were subjected to SFE- $\mathrm{CO}_{2}$ system as described by Lau et al. (2006) with some modifications. In brief, it was subjected into a $100-\mathrm{ml}$ extraction vessel and extracted with $\mathrm{SC}-\mathrm{CO}_{2}$ with the flow rate of $5 \mathrm{ml} \mathrm{min}{ }^{-1}$. SC-CO $\mathrm{CO}_{2}$ was pumped continuously from the top through the vertical extraction vessel. The extraction condition was set at $60^{\circ} \mathrm{C}, 30 \mathrm{MPa}$ and 8 hr. Next, the oil-laden stream was depressurised by expanding through a heated needle valve to atmospheric pressure, and the oil was collected in a receiver. The flow diagram of $\mathrm{SC}-\mathrm{CO}_{2}$ system is as shown in Figure 1. The extracted $\mathrm{CPO}$ and the PFF after extraction were denoted as SFE-O and SFE-F, respectively.

On the other hand, MP-O was collected from Labu palm oil mill. Generally, the palm fruits were sterilised at $140^{\circ} \mathrm{C}$ for $70-90 \mathrm{~min}$ (Akhbari et al., 2020) where the sterilised palm fruits above were also obtained at this stage, subsequently subjected to a steam-heated vessels, also known as digester. Next, the oil mixture from the digester was heated to $90^{\circ} \mathrm{C}$ for $20 \mathrm{~min}$ (Yosri et al., 2019) and allowed to separate in the clarification tank, and subsequently subjected to continuous vacuum dryer to remove water (Akhbari et al., 2020). All the palm oil samples were stored at $4^{\circ} \mathrm{C}$ and room temperature, respectively prior to analyses.
Total DF assay kit was purchased from Megazyme (Bray, Ireland). Potassium iodine and sodium thiosulphate were purchased from R\&MSdn. Bhd. (Selangor, Malaysia). CP-grade $\mathrm{CO}_{2}$ of $99.995 \%$ purity was purchased from Malaysia Oxygen Berhad (Selangor, Malaysia). Myristic acid (C14:0), palmitic acid (C16:0), stearic acid (C18:0), oleic acid (C18:1), p-anisidine, DPPH, hydrogen peroxide, ferrous (II) chloride, potassium ferricyanide, ferric (III) chloride as well as all solvents of chromatographic and analytical grades were purchased from Merck (Darmstadt, Germany).

\section{Methods}

All the tests were carried out in triplicate for each sample. Results were expressed as mean value \pm standard deviation.

\section{Quality assessment of extracted oils}

Determination of free fatty acid (FFA) content. FFA content of oil samples was determined according to Malaysian Palm Oil Board (MPOB) test method p2.5:2004 (MPOB, 2004). Approximately $3 \mathrm{~g}$ of oil sample was weighed in a conical flask and $50 \mathrm{ml}$ of isopropanol was added. About 10 drops of $1 \mathrm{~g}$ $\mathrm{ml}^{-1}$ phenolphthalein in ethanol was dripped into the flask and the solution was mixed. The mixture was then titrated with $0.1 \mathrm{~N}$ sodium hydroxide $(\mathrm{NaOH})$ until the colour changed from colourless to pink. The percentage content of FFA [as weight (wt) $\%$ of palmitic acid] was calculated as $(25.6 \mathrm{~N}$ $\mathrm{V}) / \mathrm{W}$, where $\mathrm{N}$ is the normality of $\mathrm{NaOH}$ used, $\mathrm{V}$ is the volume of titrant and $\mathrm{W}$ is the weight of the oil sample.

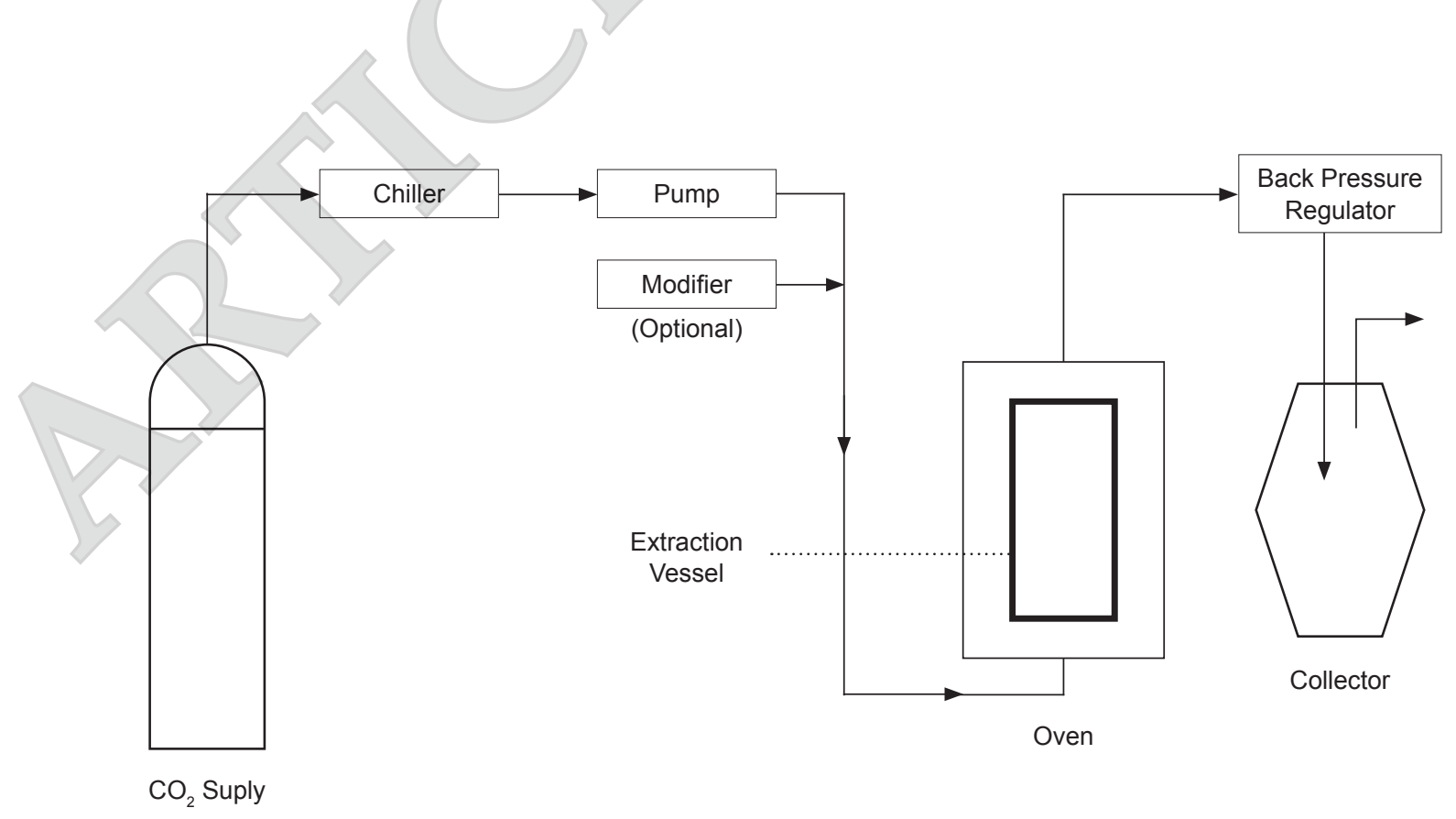


Peroxide value $(P V)$. PV of oil samples was determined from titration of the sample with sodium thiosulphate solution according to MPOB Test Method p2.3:2004 (MPOB, 2004). A starch indicator was freshly prepared by weighing $0.5 \mathrm{~g}$ of starch, followed by sequential addition of $3 \mathrm{ml}$ of distilled water and then $100 \mathrm{ml}$ of boiling water. The starch indicator was left to stand for 3 min before use. Approximately $5 \mathrm{~g}$ of oil sample was aliquoted into a conical flask. A blank was run alongside the sample. Then, $30 \mathrm{ml}$ of acetic acid:chloroform (3:2 $\mathrm{v} / \mathrm{v})$ solution and $0.5 \mathrm{ml}$ of saturated potassium iodide, potassium iodide (KI) solution were added into the conical flask. The solution was slowly mixed for $1 \mathrm{~min}$, followed by the addition of 30 $\mathrm{ml}$ of distilled water. Starch indicator was added until the solution turned to a grey-blue colour. The mixture was then titrated with $0.01 \mathrm{~N}$ sodium thiosulphate solution until the grey-blue colour faded. PV (meq $\left.\mathrm{O}_{2} \mathrm{~kg}^{-1}\right)$ was calculated as $\left[\left(\mathrm{V}_{\mathrm{S}}-\right.\right.$ $\left.\mathrm{V}_{0}\right) \mathrm{N} \mathrm{1000]/W}$, where $\mathrm{V}_{\mathrm{S}}$ is the volume of sodium thiosulphate solution used for titration with the oil sample, $\mathrm{V}_{0}$ is the volume of titrant used for the blank, $\mathrm{N}$ is the normality of sodium thiosulphate solution used and $\mathrm{W}$ is the sample weight of oil.

Phosphorus content. Phosphorus content of oil samples was determined according to MPOB Test Method Part 1b, p2.8:2004 (MPOB, 2004). Firstly, $5 \mathrm{~g}$ of the oil was weighed in a crucible and then $0.1 \mathrm{~g}$ of magnesium oxide $(\mathrm{MgO})$ was added. The mixture was charred until no more smoke was produced and was burnt in the furnace at $900^{\circ} \mathrm{C}$ for $2 \mathrm{hr}$. Once cooled to room temperature, the ash in the crucible was dissolved in $5 \mathrm{ml}$ of $6 \mathrm{~N}$ nitric acid $\left(\mathrm{HNO}_{3}\right)$, followed by the addition of $10 \mathrm{ml}$ of ammonium vanadate solution and $10 \mathrm{ml}$ of ammonium molybdate solution into the crucible. The mixture was left to stand at room temperature for $20 \mathrm{~min}$. The solution was then transferred into a quartz cuvette and the absorbance of the cell was measured at 400 $\mathrm{nm}$ against a blank containing $\mathrm{HNO}_{3^{\prime}}$ ammonium vanadate and ammonium molybdate in a ratio of 1:2:2. A calibration curve with potassium dihydrogen phosphate $\left(\mathrm{KH}_{2} \mathrm{PO}_{4}\right)$ was constructed by plotting a graph of concentration against absorbance. Briefly, the concentrations of $4,8,12$ and $16 \mu \mathrm{g} \mathrm{ml}^{-1}$ of the standard and their corresponding absorbances were determined by first reacting respectively with $1,2,3$ and $4 \mathrm{ml}$ of $0.1 \mathrm{~N} \mathrm{KH}_{2} \mathrm{PO}_{4}$ solution, followed by $10 \mathrm{ml}$ of ammonium vanadate and $10 \mathrm{ml}$ of ammonium molybdate. The solution was then marked up to $25 \mathrm{ml}$ with $6 \mathrm{~N} \mathrm{HNO}_{3}$ and the absorbance was measured at $400 \mathrm{~nm}$.

The phosphorus content, in ppm, was calculated as $(C 25 \mathrm{~A}) / \mathrm{W}$, where $C$ is the slope of the $\mathrm{KH}_{2} \mathrm{PO}_{4}$ calibration curve, $\mathrm{A}$ is the absorbance of the sample at $400 \mathrm{~nm}$ and $\mathrm{W}$ is the weight of the oil sample.

\section{Characterisation of Extracted Oils}

Fatty acid composition (FAC). FAC of the oil samples were analysed using gas chromatography equipped with a flame ionisation detector (GC-FID; Perkin Elmer, USA). Oil samples were prepared by aliquoting three drops of oil into a $1.5-\mathrm{ml}$ autosampler vial. The same volume of $0.5 \mathrm{M}$ of sodium methoxide solution was added. The sample was topped up to $1.5 \mathrm{ml}$ with hexane and was then shaken well. Samples were injected at a volume of 1 $\mu \mathrm{l}$ into the system, fitted with a BPX70 column ( $25 \mathrm{~m}$ length (L), $0.22 \mathrm{~mm}$ internal diameter (D) and 0.25 $\mu \mathrm{m}$ film thickness). The oven temperature program was initially started at $140^{\circ} \mathrm{C}$ and then ramped up to $220^{\circ} \mathrm{C}$ at a rate of $8.0^{\circ} \mathrm{C} \mathrm{min}^{-1}$ and held for $2 \mathrm{~min}$. The injector and detector temperatures were both set to $250^{\circ} \mathrm{C}$. Each sample was run for $12 \mathrm{~min}$ using purified compressed air, purified hydrogen and purified helium as carrier gases.

Total carotenoid content. The total carotenoid content of the oils was determined following MPOB Test Method p2.6:2004 (MPOB, 2004). Approximately $0.1 \mathrm{~g}$ of oil was dissolved in $250 \mathrm{ml}$ of $n$-hexane. The absorbance of the oil extract was then measured at $446 \mathrm{~nm}$ using a UV spectrometer (U-2001, Hitachi Instruments Inc., Tokyo, Japan). The total carotenoid content was calculated as $(383 E) /(I C)$, where $E$ is the observed difference in absorption between the oil and hexane, $I$ is the path length of the cell $(\mathrm{cm})$, and $c$ is the concentration used for the absorption measurement $\left(\mathrm{g} 100 \mathrm{ml}^{-1}\right)$.

Vitamin E composition. Tocopherol and tocotrienol content of the oils were determined according to the method of Che et al. (2015). The vitamin E composition was analysed using HPLC (Agilent 1100 series, Agilent Technologies, USA), equipped with a normal phase Supelco Ascentis ${ }^{\circledR}$ Si column [(150 mm (L) $\times 4.6 \mathrm{~mm}$ (D) $\times 5 \mu \mathrm{m}$ particle size)]. The HPLC system was coupled to a fluorescence detector with the detection wavelengths for excitation and emission set at $270 \mathrm{~nm}$ and $315 \mathrm{~nm}$, respectively. A mixture of $n$-heptane and ethyl acetate at 97:3\% $(\mathrm{v} / \mathrm{v})$ was used as the mobile phase.

Sterol composition and squalene content. The sterol composition and squalene content were concurrently determined according to the method by Lau et al. (2006). A gas chromatograph (GC, 7890B Agilent, Agilent Technologies, USA) with a CP9078 - select biodiesel for glycerides, UM + $2 \mathrm{~m}$ RG column [15 m (L) x $320 \mu \mathrm{m}$ (D) x $0.1 \mu \mathrm{m}$ (film)] coupled to a flame ionisation detector was used. Helium was used as the carrier gas with a flow rate of $5 \mathrm{ml} \mathrm{min}$. The temperatures of the injector, detector and oven were set at $50^{\circ} \mathrm{C}, 380^{\circ} \mathrm{C}$ and $370^{\circ} \mathrm{C}$, respectively. Identification of sterol 
composition and squalene content in the oils was done via comparison of their retention times with commercial standards, cholesterol and squalene.

\section{Antioxidant Assays}

Extraction of polar compounds from oils. The extraction of polar compounds from oil samples was performed following the method described by Radhia et al. (2017) with some modifications. Approximately $1 \mathrm{~g}$ of oil sample was weighed in a 2-ml microcentrifuge tube, followed by addition of $1 \mathrm{ml}$ of methanol:water $(80: 20 \mathrm{v} / \mathrm{v})$ which was used as the extraction solvent. Herewith, the methanol:water (80:20 v/v) was referred to as 'extraction solvent'.

The oil-solvent mixture was vortexed for $10 \mathrm{~min}$ and was then left to stand until two layers separated $(\sim 1 \mathrm{hr})$. The upper methanolic layer was collected via careful pipetting. The extraction process was repeated twice. The oil extracts were combined and stored in a scintillation vial at $4^{\circ} \mathrm{C}$ for subsequent assays. The concentration of the extracts was noted as $0.33 \mathrm{~g} \mathrm{ml}^{-1}$. For DPPH radical scavenging assay, the extracts used were collected from a single extraction (concentration of $1.0 \mathrm{~g} \mathrm{ml}^{-1}$ ) and was diluted accordingly. The extracts were named according to the oils (e.g. SFE-O extract, HEX-O extract or MP-O extract), or otherwise referred to as 'oil extracts'.

Total phenolic content (TPC). Determination of TPC in the oil extracts was done using the FolinCiocalteau (FC) method as described by Abdullah et al. (2018).

Total flavonoid content (TFC). TFC of the oil extracts was determined following the aluminum chloride $\left(\mathrm{AlCl}_{3}\right)$ colorimetric method described by Radhia et al. (2017) where rutin hydrate was used as the standard.

2,2-diphenyl-1-picrylhdrazyl (DPPH) radical scavenging assay. DPPH radical scavenging assay was conducted following the method described by Teh et al. (2013) using ascorbic acid as the standard drug.

Hydrogen peroxide $\left(\mathrm{H}_{2} \mathrm{O}_{2}\right)$ scavenging assay. $\mathrm{H}_{2} \mathrm{O}_{2}$ scavenging activity of the phenolic extracts was determined according to the method of Keser et al. (2012).

Ferrous ion chelating (FIC) assay. FIC activity of the extracts was determined according to the method described by Mah et al. (2017).

Ferric reducing antioxidant power (FRAP) assay. FRAP of the extracts was performed following the protocol by Mah et al. (2017) using ascorbic acid as the standard drug.

\section{Fibre Compositional Analysis}

Compositional analysis of holocellulose was performed according to the method described by Then et al. (2014). The $\alpha$-cellulose content was then determined following the ASTM D1103-60 (1978) method. The hemicellulose content of the fibre was calculated as the difference between the content of holocellulose and $\alpha$-cellulose. Lignin content of fibre samples was determined according to ASTM D110696 (2007).

\section{Dietary Fibre (DF) Analysis}

Determination of TDF, IDF and SDF contents was performed according to AOAC Official Method 991.43.

\section{Statistical Analysis}

Statistical analyses were performed using GraphPad Prism 7. Statistical tests such as Student's $\mathrm{t}$ test, one-way analysis of variance (ANOVA) and Tukey post-hoc tests were performed to compare data at $5 \%$ significance level $(p<0.05)$.

\section{RESULTS AND DISCUSSION}

Evaluation of physical and chemical properties of palm oil such as its FFA content, PV, phosphorus content and FAC provides fundamental information on the quality of the oil. These aspects are particularly important to gauge market acceptability, usefulness in downstream technological processes, shelf life, and the overall value of palm oil (Ji et al., 2011). The FFA, PV and phosphorus contents of the HEX-O, SFE-O and MP-O are summarised in Table 1 while the FAC of the oil samples is recorded in Table 2.

Among various quality parameters, FFA content is an excellent indicator of oil deterioration, where at high levels of FFA, sensory characteristics and nutritional benefits of the edible oil are altered due to oil rancidity. Triglycerides (TG) are composed of a glycerol molecule bound to three fatty acids molecules where TG has been reported to be prone to hydrolyse in an autocatalytic oxidation reaction to release the FFA and therefore, FFA content generally increases with time and storage period of the oil (Mizushima and Kobayashi, 1968). Consequently, FFA are considered to be pro-oxidants and is commonly correlated to the economic value of edible oils, often representative of the quality index for storage length, marketing and production of palm oil (Akihisa et al., 2000). The FFA content of SFE-O and HEX-O was below $1 \%$ at $0.59 \pm 0.09 \%$ and $0.56 \pm 0.04 \%$, respectively, while the FFA content of MP-O was significantly higher at $3.39 \pm 0.09 \%$ $(p<0.05)$ (Table 1). Experimental FFA values for SFE-O 
and HEX-O were also comparable to the published literature where SFE-O and HEX-O were reported to have an average of $0.61 \%$ and $0.37 \%$, respectively (Lau et al., 2006). The FFA content of MP-O, on the other hand, was significantly higher than SFE-O and HEX-O where the former was comparable to reported values that range from $3.15 \%$ to $4.60 \%$ (Lau et al., 2006). Hence, it is possible to infer that hexane extraction or SFE produce better quality palm oil compared to the conventional mechanical pressing. The FFA content for all samples is satisfactory as they are below the maximum acceptable FFA content of 5\%, as specified by Palm Oil Refiners Association of Malaysia (PORAM) Specification. When FFA levels exceed 5\%, the oil becomes unfit for applications in the food industry and human consumption. The FFA content range of $0.5 \%-0.8 \%$ is normally encountered for edible oils especially for those used in frying. The FFA content of SFE-O and HEX-O fall within this common range, suggesting suitability of the oils to be used directly without further refining for edible purpose. CPO with low FFA content of about $0.65 \%$ has also been reported to display good physicochemical properties with high industrial applicability (Akihisa et al., 2000).

PV is a quality parameter that provides information on the oxidation state of the oil based on the measurement of primary oxidation products. The main primary oxidation products are hydroperoxides which are highly unstable and will subsequently break down into mixtures of secondary oxidation products such as aldehydes, ketones, and fatty acids. Classification of the oxidation level of vegetable oils has been proposed based on $\mathrm{PV}$, as follows: 3-5 meq $\mathrm{O}_{2} \mathrm{~kg}^{-1}$ (low), 10-12 meq $\mathrm{O}_{2} \mathrm{~kg}^{-1}$ (moderate), and 16-18 meq $\mathrm{O}_{2} \mathrm{~kg}^{-1}$ (high) oxidation levels, respectively (Zhou et al., 2008). PV of $10 \mathrm{meq}$ $\mathrm{O}_{2} \mathrm{~kg}^{-1}$ is specified to be the maximum acceptable value where vegetable oils with PV below this value is considered to be suitable for consumption whereas oil will be considered rancid if $\mathrm{PV}$ is greater than $30 \mathrm{meq} \mathrm{O}_{2} \mathrm{~kg}^{-1}$. PV of HEX-O and MP-O are 1.67 \pm 0.30 and $1.67 \pm 0.31$ meq $\mathrm{O}_{2} \mathrm{~kg}^{-1}$ oil, respectively (Table 1) while PV of SFE-O is higher at $3.24 \pm 1.07$ meq $\mathrm{O}_{2} \mathrm{~kg}^{-1}$ oil, which is higher than that previously extracted via similar method with an average PV of 1.68 meq $\mathrm{O}_{2} \mathrm{~kg}^{-1}$ oil (Lau et al., 2006). Nevertheless, statistical analyses showed no significant differences $(p>0.05)$ between the PV of SFE-O, HEX-O and MP-O; thus, the difference in PV between samples may be considered as negligible. The low PV may be associated with the presence of antioxidants in palm oils such as carotenoids and vitamin $\mathrm{E}$ (Table 4). Based on classification by Zhou et al. (2008), the three oil samples fall under the category of low oxidation level (between 3-5 meq $\mathrm{O}_{2} \mathrm{~kg}^{-1}$ ), indicating good oxidative stability.

Total phosphorus content in $\mathrm{CPO}$ represents the total phosphatides content. Phosphatides, in turn, comprises of phospholipids or gums, and inorganic phosphates. Numerous issues have been attributed to the high content of phosphorus in palm oil. Researchers have linked phosphorus content to the oxidative stability of palm oil, suggesting the contribution of oxidation of the oil by either inorganic phosphates or phospholipids and thus, negatively affecting oil quality. Goh et al. (1984) reported that problems occur during refining of palm oil such as reduced yield of oil and the diminished bleaching power of bleaching earth. Therefore, these undesired components are usually removed by degumming process during refining of palm oil in order to obtain oxidative stable edible oils. SFE-O was found to have the lowest phosphorus content of $22.09 \pm 1.55 \mathrm{ppm}$ among the samples, followed by MP-O (45.32 $\pm 5.24 \mathrm{ppm})$ and HEX-O (66.60 $\pm 4.17 \mathrm{ppm})$, where the phosphorus content of the three oil samples was significantly different $(p<0.05)$. The lowest phosphorus content of SFE-O (26 ppm) might attribute to the insolubility of polar phospholipids in the non-polar $\mathrm{CO}_{2}$ solvent. Meanwhile, phosphorus content of HEX-O was significantly higher than MP-O, which may be related to the affinity of phospholipids for hexane used in solvent extraction, resulting in the higher content when compared to extraction with physical means as that did not disrupt the membrane layer. A similar relationship was observed where the hexane-extracted CPO from residual palmpressed fibre possessed higher phosphorus content than that in the commercial CPO (Safari et al., 2015).

The FAC of an oil is particularly important for product development and subsequent product marketing as the composition strongly influences the oxidative stability of the oil. This is because the structure of TG, in terms of the proportion and arrangement of fatty acids on the glycerol backbone, affects the physicochemical properties of the oil. Oils containing fatty acids with higher degrees of unsaturation are more prone to oxidation, resulting in alterations in taste, aroma and colour of the oil, subsequently reducing the shelf life of the oil (Ji et al., 2011). One of the unique characteristics of palm oil is having equal amounts of saturated and unsaturated fatty acids as many vegetable oils have higher content of unsaturated fatty acid. SFE-O, HEX-O and MP-O have similar ratios of saturated (SFA), monounsaturated (MUFA) and polyunsaturated (PUFA) fatty acids content with about 5:4:1. Statistical analyses showed significant differences $(p<0.05)$ for SFA and MUFA between SFE-O and HEX-O with MP-O, while there were no significant differences for PUFA. The outcome indicates that the polarity of the extractive solvents i.e. $\mathrm{CO}_{2}$ and hexane had affected FAC of the oils as more non-polar fatty acids (SFA) were extracted. 
TABLE 1. QUALITY ASSESSMENT OF OIL SAMPLES

\begin{tabular}{lccc}
\hline Oil sample & FFA (\%) & PV (meq $\mathbf{O}_{2} \mathbf{~ k g}^{-1}$ oil) & Phosphorus (ppm) \\
\hline SFE-O & $0.59 \pm 0.09^{\mathrm{a}}$ & $3.24 \pm 1.07^{\mathrm{a}}$ & $22.09 \pm 1.55^{\mathrm{a}}$ \\
HEX-O & $0.56 \pm 0.04^{\mathrm{a}}$ & $1.67 \pm 0.30^{\mathrm{a}}$ & $66.60 \pm 4.17^{\mathrm{c}}$ \\
MP-O & $3.39 \pm 0.09^{\mathrm{b}}$ & $1.67 \pm 0.31^{\mathrm{a}}$ & $45.32 \pm 5.24^{\mathrm{b}}$ \\
\hline
\end{tabular}

Note: Each data represents the mean \pm SD of three independent experiments where means with different letters in the same column indicate significant differences $(p<0.05)$ among the samples. SFE-O - supercritical fluidextracted crude palm oil; HEX-O - hexane-extracted crude palm oil; MP-O - mechanically pressed crude palm oil; FFA - free fatty acid; PV - peroxide value.

TABLE 2. FATTY ACID COMPOSITION (FAC) OF OIL SAMPLES

\begin{tabular}{llccc}
\hline \multicolumn{2}{c}{ Fatty acid } & \multicolumn{3}{c}{ Composition $(\mathbf{w t} \%)$} \\
\hline & Name & SFE-O & HEX-O & MP-O \\
\hline C10:0 & Capric acid & $0.29 \pm 0.02$ & $0.06 \pm 0.04$ & $0.40 \pm 0.11$ \\
C12:0 & Lauric acid & $0.05 \pm 0.04$ & $0.03 \pm 0.00$ & $0.07 \pm 0.02$ \\
C14:0 & Myristic acid & $1.17 \pm 0.11$ & $1.03 \pm 0.00$ & $0.82 \pm 0.02$ \\
C16:0 & Palmitic acid & $45.34 \pm 0.56$ & $45.77 \pm 0.16$ & $43.16 \pm 0.15$ \\
C16:1 & Palmitoleic acid & $0.47 \pm 0.12$ & $0.53 \pm 0.18$ & $0.23 \pm 0.04$ \\
C18:0 & Stearic acid & $3.25 \pm 0.12$ & $3.32 \pm 0.05$ & $3.98 \pm 0.06$ \\
C18:1 & Oleic acid & $39.51 \pm 0.21$ & $39.56 \pm 0.21$ & $41.06 \pm 0.15$ \\
C18:2 & Linoleic acid & $9.12 \pm 0.13$ & $9.07 \pm 0.13$ & $9.57 \pm 0.13$ \\
C18:3 & Linolenic acid & $0.74 \pm 0.46$ & $0.60 \pm 0.06$ & $0.66 \pm 0.13$ \\
C20:0 & Arachidic acid & $0.06 \pm 0.07$ & $0.02 \pm 0.07$ & $0.03 \pm 0.02$ \\
\hline
\end{tabular}

Note: Each data represents the mean \pm SD of three independent experiments. SFE-O - supercritical fluid-extracted crude palm oil; HEX-O - hexane-extracted crude palm oil; MP-O - mechanically pressed crude palm oil.

Palm oil contains various important minor components such as phenolic compounds, flavonoids, vitamin $\mathrm{E}$ and carotene contents that contribute to oil stability as well as health and nutritional properties (Choo et al., 1996, Teh et al., 2020). These compounds offer a wide range of biological activities due to their potential activities in free radical scavenging, chelation of divalent cations and as antioxidants (Abdullah et al., 2018).

In the present study, TPC and TFC analyses were carried out using the $\mathrm{FC}$ and $\mathrm{AlCl}_{3}$ colorimetric methods, respectively. Both HEX-O and MP-O were observed to have very similar TPC and TFC profiles with about $75.5 \mu \mathrm{g} \mathrm{GAE} \mathrm{g}^{-1}$ oil and $10.7 \mu \mathrm{g}$ $\mathrm{RE} \mathrm{G}^{-1}$ oil, respectively, with no significant difference $(p>0.05)$ (Table 3). In contrast, the TPC and TFC of SFE-O are comparably lower than both HEX-O and MP-O. As flavonoids are phenolic compounds, it can be inferred that $12.13 \%, 14.15 \%$ and $14.26 \%$ of TPC of SFE-O, HEX-O and MP-O, respectively, are flavonoids. There were no significant differences between TFC of all samples, which suggest that oil extraction methods did not substantially affect the extraction of flavonoids. Meanwhile, the difference of TPC between samples may be associated with the ability of the oil extraction systems i.e. hexane extraction, SFE or mechanical pressing, to simultaneously extract different types of phenolic components from the palm fruit. Furthermore, the source of the palm oil may also affect the TPC as described in a recent study which reported that $\mathrm{CPO}$ contains 31.20-70.18 ppm of phenolics depending on the palm oil mill where the oil sample was collected from (Abdullah et al., 2018).

The content of minor components in palm oil, namely vitamin $\mathrm{E}$ and carotenes, as well as squalene and sterols content were also analysed and presented in Table 4. The MP-O had the highest (1868.9 ppm) minor components, followed by HEX-O (1360.2 $\mathrm{ppm})$ and SFE-O (1299.0 ppm). The results are in line with the literature reported that palm oil contains an average of 500-700 ppm of carotenoids (Choo et al., 1996). However, in term of vitamin $\mathrm{E}$, squalene and sterols, the concentrations were remarkably low compared to the literature data which were 600-1000 ppm of vitamin E, 421-979 ppm of squalene and 250-650 ppm of sterols (Choo et al., 1996, Lau et al., 2006). The differences in the concentrations might be attributed to the growth conditions, maturity and source of the palm fruits used (El Sayed, 2000).

The presence of the above phytonutrients in the oil is crucial to maintain oil stability, prolong shelf-life, and to provide health benefits from its dietary consumption although its proportion in 
palm oil is less than $1 \%$. The synergistic antioxidant action of vitamin $\mathrm{E}$ and carotenoids has also been documented in literature where the combination of both compounds produce an improved overall antioxidant effect by the inhibition of lipid oxidation (Morel et al., 2002). Moreover, as the presence of antioxidants can affect the oxidative stability of the oil, the relatively lower average phytonutrient concentration of SFE-O may also explain the higher PV of the oil compared to HEX-O and MP-O (Ji et al., 2011).

The DPPH radical scavenging activity of the oil extracts increase in a dose-dependent relationship. The standard compound, ascorbic acid, demonstrated significant radical scavenging activity with an $\mathrm{EC}_{50}$ of $0.02 \mathrm{mg} \mathrm{ml}^{-1}$ which is much lower compared to the $\mathrm{EC}_{50}$ of $242.67,214.67$ and $348.33 \mathrm{mg} \mathrm{ml}^{-1}$ for the extracts of SFE-O, HEX-O and MP-O, respectively (Table 5). Among the oil samples, the HEX-O extract displayed the lowest $\mathrm{EC}_{50}$ which means the highest DPPH radical scavenging activity, followed by SFE-O and MP-O. These results highlighted the hydrogen donating ability of the phenolic compounds in the extracts. Surprisingly, MP-O which had the highest content of vitamin E among the three samples was found to have the lowest DPPH radical scavenging activity despite vitamin E exhibiting effective free radical scavenging activity, while HEX-O with the lowest vitamin E content displayed highest radical scavenging activity. This contradicting finding may be linked to the nature of vitamin $\mathrm{E}$ as lipidsoluble compounds. Consequently, vitamin $\mathrm{E}$ is not maximally extracted from the oil using the polar extraction solvent which were methanol:water $(80: 20 \mathrm{v} / \mathrm{v})$, in this case and therefore had minimal contribution to antioxidant activity. A similar inference may be extended to the lipophilic squalene which is extracted by the polar extraction solvent. The outcome postulates that both SFE-O and HEX-O contain similar profile of methanolic extract of carotenoids, vitamin, squalene and sterols but different from MP-O.

$\mathrm{H}_{2} \mathrm{O}_{2}$ is classified as a non-radical reactive oxygen species where scavenging activity is important to curb the generation of reactive hydroxyl radicals that occur via the Fenton reaction: $\mathrm{Fe}^{2+}+\mathrm{H}_{2} \mathrm{O}_{2}$ $\rightarrow \mathrm{Fe}^{3+}+\mathrm{OH}^{-}+\mathrm{OH} \bullet$ (Balasundram et al., 2005). The scavenging ability has been correlated to the electron-donating capacity of phenolic compounds which removes the odd number of electrons of the hydroxyl radical (Balasundram et al., 2005). The standard compound, $\alpha$-tocopherol, had $\mathrm{H}_{2} \mathrm{O}_{2}$ scavenging activity of $52.42 \pm 3.45 \%$ at $1 \mathrm{mg} \mathrm{ml}^{-1}$ (Table 5) which is comparable to the value reported by Keser et al. (2012) of 44.58\%. The $\mathrm{H}_{2} \mathrm{O}_{2}$ scavenging activity of the oil extracts can be ranked as follows: HEX-O > SFE-O > MP-O at a concentration of $1 \mathrm{mg} \mathrm{ml}^{-1}$, with no significant differences between the scavenging activities of the three oil extracts $(p>0.05)$. In contrast to previous publications by Mah et al. (2017) and Abdullah et al. (2018) that highlighted positive correlations between TPC and antioxidant activity, no direct relationship can be observed between TPC and TFC with the scavenging activity of the extracts. Different active compounds may exhibit antioxidant activities via various mechanisms of action. Thus, combination

TABLE 3. TOTAL PHENOLIC CONTENT (TPC) AND TOTAL FLAVONOID CONTENT (TFC) OF OIL EXTRACTS

\begin{tabular}{lcc}
\hline Oil extract & TPC $\left(\mu\right.$ g GAE g $^{-1}$ oil $)$ & TFC $\left(\mu\right.$ RE $^{-1}$ oil $)$ \\
\hline SFE-O & $64.97 \pm 1.12^{\mathrm{a}}$ & $7.88 \pm 0.78^{\mathrm{a}}$ \\
HEX-O & $75.98 \pm 1.28^{\mathrm{b}}$ & $10.75 \pm 3.80^{\mathrm{a}}$ \\
MP-O & $75.11 \pm 4.08^{\mathrm{b}}$ & $10.71 \pm 0.31^{\mathrm{a}}$ \\
\hline
\end{tabular}

Note: Each data represents the mean \pm SD of three independent experiments where means with different letters in the same column indicate significant differences $(p<0.05)$ among the samples. SFE-O supercritical fluid-extracted crude palm oil; HEX-O - hexane-extracted crude palm oil; MP-O mechanically pressed crude palm oil; GAE - gallic acid equivalent; RE - rutin hydrate equivalent.

TABLE 4. CAROTENOID, VITAMIN E, SQUALENE AND STEROLS CONTENTS OF OIL SAMPLES

\begin{tabular}{lcccc}
\hline Oil Samples & Carotenoids $(\mathbf{p p m})$ & Vitamin E (ppm) & Squalene $(\mathbf{p p m})$ & Sterols $(\mathbf{p p m})$ \\
\hline SFE-O & $540.0 \pm 21.0^{\mathrm{a}}$ & $495.0 \pm 7.9^{\mathrm{b}}$ & $129.3 \pm 1.5^{\mathrm{a}}$ & $134.7 \pm 3.2^{\mathrm{a}}$ \\
HEX-O & $583.3 \pm 13.0^{\mathrm{a}}$ & $471.3 \pm 8.1^{\mathrm{a}}$ & $171.3 \pm 15.8^{\mathrm{b}}$ & $134.3 \pm 1.2^{\mathrm{a}}$ \\
MP-O & $633.3 \pm 7.2^{\mathrm{b}}$ & $931.3 \pm 2.5^{\mathrm{c}}$ & $130.0 \pm 10.0^{\mathrm{a}}$ & $174.3 \pm 15.9^{\mathrm{b}}$ \\
\hline
\end{tabular}

Note: Each data represents the mean \pm SD of three independent experiments where means with different letters in the same column indicate significant differences $(p<0.05)$ among the samples. SFE-O supercritical fluid-extracted crude palm oil; HEX-O - hexane-extracted crude palm oil; MP-O mechanically pressed crude palm oil. 
of antioxidant assays gives better insights on the antioxidant reactions, especially when compounds are present as a mixture.

Iron in its ferrous form, $\mathrm{Fe}^{2+}$ is capable of initiating and propagating numerous radical reactions, such as the generation of hydroxyl radicals via the Fenton reaction as described earlier. Iron may be released from storage and iron-binding proteins during altered physiological states which may contribute to the damage and development of more serious disease states due to the activity of radicals. Thus, iron chelators are essential to prevent and halt radical and reactive oxygen species generation and propagation. The standard compound ethylenediaminetetraacetic acid (EDTA), known for its chelating activity, was found to have an $\mathrm{EC}_{50}$ of $54.33 \pm 1.53 \mu \mathrm{g} \mathrm{ml}^{-1}$ which is higher than the literature data which was $10 \mu \mathrm{g}$ $\mathrm{ml}^{-1}$ (Chai et al., 2014). SFE-O extracts displayed the highest chelation activity of $47.96 \pm 1.24 \%$ at sample concentration of $0.33 \mathrm{~g} \mathrm{ml}^{-1}$. In contrast, MP-O and HEX-O showed lower activity of $32.35 \pm 1.80 \%$ and $17.48 \pm 2.43 \%$, respectively, where the latter had the lowest chelating power among the three oil extracts. The FIC of SFE-O, HEX-O and MP-O are significantly different from one another $(p<0.05)$. Previous research on carotenoids identify these compounds to possess chelating capacities (Sen Gupta and Ghosh, 2013), however, the outcome is not in good agreement with the literature. Vitamin E, squalene and sterols have not been associated with significant chelating activity. The distinct chelating activity of the oil extracts could hence be correlated to the synergistic and antagonistic effects on varying amount and types of compounds present as the consequence of using different oil extraction methods.

FRAP assay is based on the reducing power of active compounds to reduce the $\mathrm{Fe}^{3+}$-ferricyanide complex to the ferrous state. This assay evaluates the ability of compounds to maintain the redox status in the physiological body (FDA Food Code, 2013). FRAP of the palm oil extracts was expressed as ascorbic acid equivalents (AE), determined from the plotted ascorbic acid calibration curve. The highest antioxidant capacity was shown by HEX-O

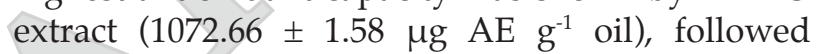
closely by MP-O $\left(1043.33 \pm 9.06 \mu \mathrm{g} \mathrm{AE} \mathrm{g}^{-1}\right.$ oil). On the other hand, SFE-O exhibited the weakest antioxidant capacity of $960.79 \pm 1.10 \mu \mathrm{g} \mathrm{AE} \mathrm{g}{ }^{-1}$ oil. The total antioxidant capacities of the oil extracts are significantly different from each other $(p<0.05)$. A relationship between TPC-TFC and FRAP of the oils can be observed, contrary to results from other antioxidant assays. For example, HEX-O with the highest TPC and TFC demonstrated the highest total antioxidant capacity. This trend was also observed for MP-O and SFE-O which is in accordance with a previous study demonstrating the positive linear relationship of TPC-TFC and FRAP where a higher TPC and TFC is associated with higher antioxidant capacity (FDA Food Code, 2013).

Although SFE-O, HEX-O and MP-O extracts had similar TPC and TFC, the differences in activity from the various antioxidant assays conducted suggest varying concentrations or the presence of different types of phenolic compounds in the palm oils which may be due to the different extraction methods. The biological activities as antioxidants, free radical scavengers and ion chelators of the oils are the result of the combined action of all phenolic compounds in the extracts; consequently, distinct composition of compounds in the oil extracts of SFE-O, HEX-O and MP-O had resulted in the exhibition of different antioxidant activities (Balasundram et al., 2005). This explanation could also be extended to SFE-O, which was found to possess different TPC, TFC and antioxidant activities compared to HEX-O and MP-O. For example, despite SFE-O having the lowest TPC and TFC content compared to HEX-O and MP-O, it demonstrated higher FIC ability $(47.96 \pm 1.24 \%)$ and had the second highest DPPH and $\mathrm{H}_{2} \mathrm{O}_{2}$ radical scavenging activity. Comparing the antioxidant activities of the oil extracts across the various assays performed, it may be hypothesised that extraction method influences the type and composition of phenolic compounds present in the oil. Regardless, the palm oils evidently exhibit antioxidant activities through different mechanisms. The generation of free radicals may overwhelm the body's natural protective defense and cause oxidative stress despite the human body being capable of producing its own endogenous antioxidants where oxidative stress has been implicated in the development of various diseases including cancer, atherosclerosis and diabetes (Gopalakrishnan et al., 1980). Thus, incorporation of antioxidant-rich food products such as palm oil into the daily diet offers nutritional and health benefits such as the protection against free radicals and oxidative stress (Soundararajan and Sasidharan, 2012).

The fibre composition of SFE-F and HEX-F is similar where the major components in both fibres are hemicellulose $(23.83 \%-24.10 \%)$, followed by lignin $(22.63 \%-24.52 \%)$ and $\alpha$-cellulose $(16.24 \%$ $16.78 \%$ ). This is not surprising as oil palm biomass is often referred to as lignocellulosic material. The lignin content of the fibres is similar to published data for PFF with the range of 22.0\%25.7\% (Abdul Aziz et al., 2011; Yasim-Anuar et al., 2016). On the other hand, literature data showed that hemicellulose content in PFF ranged from $31.80 \%$ to $33.10 \%$ (Abdul Aziz et al., 2011; Nordin et al., 2013; Yasim-Anuar et al., 2016) while cellulose content in PFF ranged from $34.5 \%$ to $43.00 \%$ (Abdul Aziz et al., 2011; Nordin et al., 2013; Yasim-Anuar et al., 2016) which is two to three folds higher than 
in SFE-F and HEX-F. These published findings were comparably higher compared to SFE-F and HEX-F. Various publications highlighted the discrepancies and contrasting findings of fibre composition despite being from the same plant source. Factors such as plant age, geography, soil and other climate variations may alter the fibre composition which may explain the lower cellulose and hemicellulose content in SFE-F and HEX-F compared to the reported data. In addition, the sum of fibre constituents may not necessarily add up to $100 \%$, as observed in the present study, as some components were not traced to a measurable quantity (Komuraiah et al., 2014).

The high composition of lignocellulosic components i.e. cellulose, hemicellulose and lignin in PFF suggests a potential source of DF. Analysis of DF content in PFF after oil extraction revealed a relatively high TDF content of SFE-F and HEX-F of $59.26 \pm 0.54$ and $55.32 \pm 1.90 \%$, respectively. Results from this analysis is highly comparable with the fibre compositional analyses which identified SFE-F and HEX-F to contain $64.59 \%$ and $63.51 \%$ of IDF (cellulose, hemicellulose and lignin), respectively (Table 6). Functional and sensorial properties of food products are most commonly described with the ratio of IDF to SDF (Shen et al., 2005). The IDF:SDF ratio of HEX-F is 22.09 whereas the ratio for SFE-F is significantly higher by at least five-fold at 114.78 (Table 6) where the ratios imply a higher content of IDF in the latter. The IDF:SDF ratio of HEX-F is comparable to those of several food items such as beans, vegetables and fruits that are popular and established sources of DF. For example, IDF:SDF ratio of mung beans, cooked yellow corn, organically grown wheat cereal and mooth Cayenne pineapple is in the range of 22.17 to 35.5 (Safari et al., 2015; Shen et al., 2005; Kanterman et al., 2012). Meanwhile, the IDF:SDF ratio of SFE-F is comparable to the ratio of split peas which is 117.3 (Safari et al., 2015).

Overall, this characterisation study of PFF highlighted the potential of PFF as a source of DF. As the daily intake of DF is still below recommended levels, incorporation of PFF into human diet combats this problem while concurrently maximising the functional and economic potential of OPB. Further investigation is therefore recommended to continue this effort for the comprehensive utilisation of the $\mathrm{PFF}$ in the field of nutrition.

TABLE 5. ANTIOXIDANT PROPERTIES OF OIL EXTRACTS

\begin{tabular}{|c|c|c|c|c|}
\hline \multirow[b]{3}{*}{ Oil extracts } & \multirow[b]{3}{*}{$\begin{array}{c}\mathrm{EC}_{50} \text { towards DPPH } \\
\text { radicals }\left(\mathrm{mg} \mathrm{ml}^{-1}\right)\end{array}$} & \multicolumn{3}{|c|}{ Concentrations } \\
\hline & & $1 \mathrm{mg} \mathrm{ml}^{-1}$ & \multicolumn{2}{|c|}{$0.33 \mathrm{~g} \mathrm{ml}^{-1}$} \\
\hline & & $\begin{array}{l}2 \text { scavenging } \\
\text { ctivity }(\%)\end{array}$ & $\begin{array}{c}\text { Ferrous ion } \\
\text { chelating activity } \\
(\%)\end{array}$ & $\begin{array}{c}\text { Total antioxidant } \\
\text { capacity } \\
\text { ( } \mu \text { g ascorbic acid } \\
\text { equivalent } g^{-1} \text { oil) }\end{array}$ \\
\hline SFE-O & $242.67 \pm 6.81^{c}$ & $40.32 \pm 2.49^{a}$ & $47.96 \pm 1.24^{c}$ & $960.79 \pm 1.10^{\mathrm{a}}$ \\
\hline $\mathrm{HEX}-\mathrm{O}$ & $214.67 \pm 4.62^{b}$ & $40.55 \pm 1.46^{\mathrm{a}}$ & $17.48 \pm 2.43^{\mathrm{a}}$ & $1072.66 \pm 1.58^{c}$ \\
\hline MP-O & $348.33 \pm 2.89^{\mathrm{d}}$ & $35.65 \pm 3.33^{\mathrm{a}}$ & $32.35 \pm 1.80^{\mathrm{b}}$ & $1043.33 \pm 9.06^{\mathrm{b}}$ \\
\hline Ascorbic aci & $0.02 \pm 0.01^{\mathrm{a}}$ & - & - & - \\
\hline$\alpha$-tocopherol & - & $52.42 \pm 3.45^{\mathrm{b}}$ & - & - \\
\hline EDTA & - & - & 100 & - \\
\hline
\end{tabular}

Note: Each data represents the mean \pm SD of three independent experiments where means with different letters in the same column indicate significant differences $(p<0.05)$ among the samples. SFE-O - supercritical fluidextracted crude palm oil; HEX-O - hexane-extracted crude palm oil; MP-O - mechanically pressed crude palm oil. EDTA - ethylenediaminetetraacetic acid.

\begin{tabular}{lrr} 
& & \\
& TABLE 6. DIETARY FIBRE (DF) CONTENT OF OIL PALM FRUIT FIBRES (PFF) \\
\hline Component & Percentage content (wt $\%$ ) \\
\cline { 2 - 3 } TDF & SFE-F & $55.32 \pm 1.90$ \\
IDF & $59.26 \pm 0.54$ & $52.58 \pm 2.25$ \\
SDF & $56.24 \pm 1.40$ & $2.38 \pm 0.10$ \\
IDF:SDF ratio & $0.49 \pm 0.12$ & 22.09 \\
\hline
\end{tabular}

Note: Values are expressed as mean \pm SD from three independent experiments. Values have been corrected for ash and protein content. SFE-F - PFF after oil extraction using supercritical fluid; HEX-F - PFF after oil extraction using hexane; TDF - total dietary fibre; IDF - insoluble dietary fibre; SDF - soluble dietary fibre. 


\section{CONCLUSION}

SFE-O has good oil quality and stability where all tested quality parameters were within acceptance limit and were highly comparable to HEX-O and MP-O. SFE is thus, highly advantageous and is also a greener extraction alternative for the extraction of high-quality palm oil. Furthermore, the antioxidant activity of SFE-O extracts was akin to HEX-O and MP-O. Phenolic and flavonoid compounds, as well as vitamin E, carotenoids and squalene exist as minor components in oil with considerable antioxidant activity which are beneficial to health while also contributing to the oxidative stability of the oil. The lignocellulosic PFF remaining after CPO extraction is rich in IDF with small amounts of SDF, suggesting the potential use of PFF in nutrition. The complete utilisation of palm fruit as palm oil and fibre source is promising; thus, further studies for the incorporation of PFF in the daily diet is recommended.

\section{ACKNOWLEDGEMENT}

We would like to thank the Director-General of MPOB for permission to publish these data. This research did not receive any specific funding.

\section{REFERENCES}

Abdul Aziz, M; Uemura, Y and Sabil, K (2011). Characterization of oil palm biomass as feed for torrefaction process. Paper presented at the 2011 National Postgraduate Conference. Perak. p. 1-6.

Abdullah, F; Ismail, R; Ghazali, R and Idris, Z (2018). Total phenolic contents and antioxidant activity of palm oils and palm kernel oils at various refining processes. J. Oil Palm Res., 30: 682-692.

Akhbari, A; Kutty, P K; Chuen, O C and Ibrahim, S (2020). A study of palm oil mill processing and environmental assessment of palm oil mill effluent treatment. Environ. Eng. Res., 25: 212-221.

Akihisa, T; Yasukawa, K; Yamaura, M; Ukiya, M; Kimura, Y; Shimizu, N and Arai, K (2000). Triterpene alcohol and sterol ferulates from rice bran and their anti-inflammatory effects. J. Agric. Food Chem., 48: 2313-2319.

Alizadeh, H; Teymouri, F; Gilbert, T I and Dale, B E (2005). Pretreatment of switchgrass by ammonia fibre explosion (AFEX). Appl. Biochem. Biotechnol., 124: 1133-1141.
Amin, F R; Khalid, H; Zhang, H; Rahman, S u; Zhang, R; Liu, G and Chen, C (2017). Pretreatment methods of lignocellulosic biomass for anaerobic digestion. AMB Expr., 7: 72-83.

Anderson, J W; Baird, P; Davis, R H, Jr; Ferreri, S; Knudtson, M; Koraym, A; Waters, V and Williams, C L (2009). Health benefits of dietary fibre. Nutr. Rev., 67: 188-205.

Balasundram, N; Ai, T; Sambanthamurthi, R; Sundram, K and Samman, S (2005). Antioxidant properties of palm fruit extracts. Asia Pac. J. Clin. Nutr., 14: 319-324.

Barakat, A; Monlau, F; Solhy, A and Carrere, H (2015). Mechanical dissociation and fragmentation of lignocellulosic biomass: Effect of initial moisture, biochemical and structural proprieties on energy requirement. Appl. Energy, 142: 240-246.

Chai, T; Mohan, M; Ong, H and Wong, F (2014). Antioxidant, iron-chelating and anti-glucosidase activities of Typha domingensis Pers (Typhaceae). Trop. J. Pharm. Res., 13: 67-72.

Che, H L; Tan, D M Y; Meganathan, P; Gan, Y L; Razak, GA and Fu, JY (2015). Validation of a HPLC/ FLD method for quantification of tocotrienols in human plasma. Int. J. Anal. Chem., 2015: 1-7.

Chen, Y; Stevens, M A; Zhu, Y; Holmes, J and $\mathrm{Xu}, \mathrm{H}$ (2013). Understanding of alkaline pretreatment parameters for corn stover enzymatic saccharification. Biotechnol. Biofuels, 6: 1-10.

Choo, Y M; Yap, S C; Ooi, C K; Ma, A N; Goh, S H and Ong, A S H (1996). Recovered oil from palmpressed fibre: A good source of natural carotenoids, vitamin E and sterols. J. Am. Oil Chem. Soc., 73: 599602.

Comalada, M; Camuesco, D; Sierra, S; Ballester, I; Xaus, J; Galvez, J and Zarzuelo, A (2005). In vivo quercitrin anti-inflammatory effect involves release of quercetin, which inhibits inflammation through down-regulation of the NF-kappaB pathway. Eur. J. Immunol, 35: 584-592.

Duque, A; Manzanares, P; Ballesteros, I and Ballesteros, M (2016). Chapter 15 - Steam explosion as lignocellulosic biomass pretreatment. (Mussatto, S I ed). Biomass Fractionation Technologies for a Lignocellulosic Feedstock Based Biorefinery. Elsevier, Amsterdam.

El Sayed, K A 2000. Natural Products as Antiviral Agents. (Atta Ur, R ed). Studies in Natural Products Chemistry. Elsevier. 
Elgharbawy, A A; Alam, M Z; Moniruzzaman, M and Goto, $M$ (2016). Ionic liquid pretreatment as emerging approaches for enhanced enzymatic hydrolysis of lignocellulosic biomass. Biochem. Eng. J., 109: 252-267.

FDA Food Code (2013). Recommendations of the United States Public Health Service Food and Drug Administration. United States Public Health Service. Food and Drug Administration.

Galle, J; Quaschning, T; Seibold, S and Wanner, C (2003). Endothelial dysfunction and inflammation: what is the link? Kidney Int. Suppl., 63: S45-S49.

Goh, S H; Tong, S L; Gee, P T (1984). Inorganic phosphate in crude palm oil: Quantitative analysis and correlations with oil quality parameters. J. Am. Oil Chem. Soc., 61(10): 1601-1604.

Gopalakrishnan, C; Shankaranarayanan, D; Nazimudeen, S K; Viswanathan, S and Kameswaran, L (1980). Anti-inflammatory and CNS depressant activities of xanthones from Calophyllum inophyllum and Mesua ferrea. Indian J. Pharmacol., 12: 181-191.

Hendriks, A T W M and Zeeman, G (2009). Pretreatments to enhance the digestibility of lignocellulosic biomass. Bioresour. Technol., 100: 1018.

Ialenti, A; Ianaro, A; Moncada, S and Di Rosa, M (1992). Modulation of acute inflammation by endogenous nitric oxide. Eur. J. Pharmacol., 211: 177182.

Ji, G; Yang, Q; Hao, J; Guo, L; Chen, X; Hu, J; Leng, L and Jiang, Z (2011). Anti-inflammatory effect of genistein on non-alcoholic steatohepatitis rats induced by high fat diet and its potential mechanisms. Int. Immunopharmacol., 11: 762-768.

Kanterman, J; Sade-Feldman, M; Baniyash, M (2012). New insights into chronic inflammation-induced immunosuppression. Semin. Cancer Biol., 22: 307-318.

Keser, S; Celik, S; Turkoglu, S; Yilmaz, O and Turkoglu, I (2012). Hydrogen peroxide radical scavenging and total antioxidant activity of hawthorn. Chem. J., 2: 9-12.

Komuraiah, A; Shyam Kumar, N and Durga Prasad, B (2014). Chemical composition of natural fibres and its influence on their mechanical properties. Mech. Compos. Mater., 50: 359-376.

Kushairi, A; Ong-Abdullah, M; Nambiappan, B; Hishamuddin, E; Izuddin, Z; Ghazali, R;
Subramaniam, V; Sundram, S and Ghulam Kadir, A P (2019). Oil palm economic performance in Malaysia and R\&D progress in 2018. J. Oil Palm Res., 31: 165-194.

Kwong, H C; Chidan Kumar, C S; Mah, S H; Chia, T S; Quah, C K; Loh, Z H; Chandraju, S and Lim, G K (2017). Novel biphenyl ester derivatives as tyrosinase inhibitors: Synthesis, crystallographic, spectral analysis and molecular docking studies. PLoS ONE, 12: e0170117.

Lau, H L N; Choo, Y M; Ma, A N and Chuah, C H (2006). Quality of residual oil from palm-pressed mesocarp fibre (Elaies guineensis) using supercritical $\mathrm{CO}_{2}$ with and without ethanol. J. Am. Oil Chem. Soc., 83: 893-898.

Li, Z; Chen, C H; Hegg, E L and Hodge, D B (2013). Rapid and effective oxidative pretreatment of woody biomass at mild reaction conditions and low oxidant loadings. Biotechnol. Biofuels, 6: 119-127.

Lin, Z; Liu, L; Li, R and Shi, J (2012). Screw extrusion pretreatments to enhance the hydrolysis of lignocellulosic biomass. J. Microb. Biochem. Technol., S12: 1-5.

Loh, S K (2017). The potential of the Malaysian oil palm biomass as a renewable energy source. Energy Convers. Manag., 141: 285-298.

Mah, S H; Teh, S S and Ee, G C L (2017). Antiinflammatory, anti-cholinergic and cytotoxic effects of Sida rhombifolia. Pharm. Biol., 55: 920-928.

Mahesar, S A; Sherazi, S T H; Khaskheli, A R; Kandhro, A A and Uddin, S (2014). Analytical approaches for the assessment of free fatty acids in oils and fats. Anal. Methods, 6: 4956-4963.

Mizushima, Y and Kobayashi, M (1968). Interaction of anti-inflammatory drugs with serum proteins, especially with some biologically active proteins. $J$. Pharm. Pharmacol., 20: 169-173.

Morel, C; Seraphin, D; Teyrouz, A; Larcher, G; Bouchara, J P; Litaudon, M; Richomme, $\mathrm{P}$ and Bruneton, J (2002). New and antifungal xanthones from Calophyllum caledonicum. Planta Med., 68: 41-44.

MPOB (2004). MPOB Test Methods - A Compendium of Test on Palm Oil Products, Palm Kernel Products, Fatty Acids, Food Related Products and Others (Kuntom, A.; Siew, W L; Tan. Y A; Idris, N A; Yusof, M; Tang, T S and Amri $\mathrm{N}$ eds.). MPOB, Bangi.

Noparat, P; Prasertsan, P; O-Thong, S and Pan, $X$ (2015). Dilute acid pretreatment of oil palm 
trunk biomass at high temperature for enzymatic hydrolysis. Energy Procedia, 79: 924-929.

Nordin, N I A; Ariffin, H; Andou, Y; Hassan, M A; Shirai, Y; Nishida, H; Yunus, W M Z W; Karuppuchamy, S and Ibrahim, N A (2013). Modification of oil palm mesocarp fibre characteristics using superheated steam treatment. Molecules (Basel, Switzerland), 18: 9132-9146.

Park, Y C; Kim, T H and Kim, J S (2017). Effect of organosolv pretreatment on mechanically pretreated biomass by use of concentrated ethanol as the solvent. Biotechnol. Bioprocess Eng., 22: 431439.

Pielhop, T; Amgarten, J; von Rohr, P R and Studer, M H (2016). Steam explosion pretreatment of softwood: the effect of the explosive decompression on enzymatic digestibility. Biotechnol. Biofuels, 9: 152-163.

Radhia, F; Lekbir, A; Ouadah, H; Kahoul, M A; Khlalfa, L; Laroui, $\mathrm{S}$ and Alloui-Lombarkia, $\mathrm{O}$ (2017). Effect of extraction solvent on total phenolic content, total flavonoid content, and antioxidant activities of Algerian pomace olive oil. Int. Food Res. J., 24: 2295-2303.

Ruiz-Marcial, C; Reyes Chilpa, R; Estrada, E; ReyesEsparza, J; Farina, G G and Rodriguez-Fragoso, L (2007). Antiproliferative, cytotoxic and antitumour activity of coumarins isolated from Calophyllum brasiliense. J. Pharm. Pharmacol., 59: 719-725.

Safari, F; Tavasoli, A; Ataei, A and Choi, J-K (2015). Hydrogen and syngas production from gasification of lignocellulosic biomass in supercritical water media. Int. J. Recycl. Org. Waste Agricult., 4: 121-125.

Sen Gupta, S and Ghosh, M (2013). In vitro antioxidative evaluation of $\alpha$ - and $\beta$-carotene isolated from crude palm oil. J. Anal. Methods Chem., 2013: 351671-351671.

Shen, Y C; Wang, L T; Khalil, A T; Chiang, L C and Cheng, P W (2005). Bioactive pyranoxanthones from the roots of Calophyllum blancoi. Chem. Pharm. Bull. (Tokyo), 53: 244-247.

Soundararajan, V and Sasidharan, S (2012). Antioxidant activity of Elaeis guineensis leaf extract: An alternative nutraceutical approach in impeding aging. APCBEE Procedia, 2: 153-159.

Souza, M do C; Beserra, A M S; Martins, D C; Real, V V; Santos, R A; Rao, V S; Silva, R M and Martins, $\mathrm{D} \mathrm{T}$ (2009). In vitro and in vivo anti-helicobacter pylori activity of Calophyllum brasiliense camb. J. Ethnopharmacol., 123: 452-458.

Subhedar, P B and Gogate, P R (2016). Chapter 6 Use of ultrasound for pretreatment of biomass and subsequent hydrolysis and fermentation. Biomass Fractionation Technologies for a Lignocellulosic Feedstock Based Biorefinery. (Mussatto, S I ed). Elsevier, Amsterdam.

Teh, S S; Ee, G C L; Mah, S H; Yong, Y K; Lim, Y M; Rahmani, M and Ahmad, Z (2013). In vitro cytotoxic, antioxidant, and antimicrobial activities of Mesua beccariana (Baill.) kosterm., Mesua ferrea Linn., and Mesua congestiflora extracts. BioMed Res. Int., 2013: 1-9.

Teh, S S; Mah, S H and Razak, RAA (2020). Oxidative stability and physicochemical properties of palm olein. J. Oil Palm Res., 32: 518-525.

Then, Y Y; Ibrahim, N A; Zainuddin, N; Ariffin, H; Wan Yunus, W M Z; Chieng, B W (2014). Surface modifications of oil palm mesocarp fiber by superheated steam, alkali, and superheated steamalkali for biocomposite applications. BioResources, 9 (4): 7467-7483.

Yasim-Anuar, TA T; Ariffin, H; Norrrahim, MN F and Hassan, M A (2016). Factors affecting spinnability of oil palm mesocarp fibre cellulose solution for the production of microfibre. BioResources, 12(1): 715734.

Yeo, J Y J; How, B S; Teng, S Y; Leong, W D; Ng, W P Q; Lim, C H; Ngan, S L; Sunarso, J and Lam, H L (2020). Synthesis of sustainable circular economy in palm oil industry using graph-theoretic method. Sustainability, 12: 8081.

Yosri, M S; Syahril Anuar, M R; Nik Suhaimi, M H; Muhammad Zaidy, A; Mohammed Faisal, M Y and Ahmad Jaril, A (2019). Screw press operation optimisation for oil and kernel recovery enhancement. Palm Oil Engineering Bulletin, 130: p. 18-26.

Zheng, Y; Lin, H-M; Wen, J; Cao, N; Yu, X and T Tsao, G (1995). Supercritical carbon dioxide explosion as a pretreatment for cellulose hydrolysis. Biotechnol. Lett., 17: 845-850.

Zhou, H Y; Shin, E M; Guo, L Y; Youn, U J; Bae, K; Kang, S S; Zou, L B and Kim, Y S (2008). Antiinflammatory activity of 4-methoxyhonokiol is a function of the inhibition of iNOS and COX-2 expression in RAW 264.7 macrophages via NFkappaB, JNK and p38 MAPK inactivation. Eur. J. Pharmacol., 586: 340-349. 